\title{
El imposible más allá del cuerpo Blanco: sobre el amor, la política y la crítica descolonial*
}

Julio César Mazo González**

Artículo de investigación sobre el cuerpo Blanco como representación de la transformación civilizatoria de Occidente, y el amor como renovación crítica de la política descolonial.

Recibido: 6 de mayo de 2020

Evaluado: 2 de diciembre de 2020

Aceptado: 13 de enero de 2021

Publicado: 1 de julio de 2021

Citar como:

Mazo, J. (2021). El imposible más allá del cuerpo Blanco: sobre el amor, la política y la crítica descolonial. Hallazgos, 18(36), 103-133.

https://doi.org/10.15332/2422409X.5794

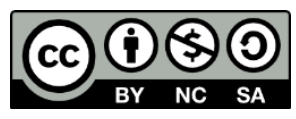

\section{Resumen}

El propósito fundamental de este artículo es doble. Por un lado, se trata de examinar críticamente las claves - entiéndase, los "privilegios", los excesos, pero también los agotamientos - del proyecto moderno-colonial a través de lo que Houria Bouteldja llama el cuerpo Blanco, es decir, la

\footnotetext{
* Artículo de investigación suscrito a la investigación en curso "Los cuerpos de la política. Hacia una revisión crítica de los afectos como renovación política descolonizadora", apoyada por el programa de Filosofía de la Facultad de Ciencias Sociales y Humanas, Universidad Externado de Colombia.

** Magíster en Literatura y Cultura del Instituto Caro y Cuervo. Docente investigador del programa de Filosofía de la Universidad Externado de Colombia.

Correo electrónico: julio.mazo@uexternado.edu.co

ORCID: https://orcid.org/0000-0002-6826-3881
}

Hallazgos

ISSN: 1794-3841 | e-ISSN: 2422-409X | DOI: https://doi.org/10.15332/2422409X

Vol. 18 N.o 36| julio-diciembre del 2021 
representación de la avasallante transformación civilizatoria de Occidente, pero también, en su otro extremo, del esencialismo antisitémico en el que buena parte de la crítica descolonial ha caído. En segundo lugar, este examen espera dar luces sobre una reevaluación crítica y dialógica del amor, de la imposibilidad que sobre él han hecho pesar el circuito mercantil y los códigos de dominación racial propios de la supremacía blanca. De este modo, lo ubica en el corazón de una renovada revolución descolonial, que ve en el antagonismo - el conflicto inextinguible que le sigue al encuentro con la diferencia - el único rescate posible de la democracia, pero, sobre todo, de una verdadera e incluso paradójica, alianza entre aquellos que el cuerpo Blanco ha llevado al límite de la opresión y la aparente segmentación. Esto recuerda, por último, que el amor revolucionario es el único que, hoy por hoy, ayuda a restituir la idea de voluntad como un proceso esencialmente combativo.

Palabras clave: Amor; Antagonismo; Cuerpo Blanco; Crítica descolonial; Política; Voluntad.

\section{The impossible beyond the White body: on love, politics and decolonial critique}

\section{Abstract}

The fundamental purpose of this article is twofold. On the one hand, to critically examine keys -meaning the "privileges", the excesses but also the exhaustions - of the modern-colonial project, through what Houria Boutelidia calls the White body, that is, the representation of the West's overwhelming civilizational transformation, but also, on the other hand, the anti-systemic essentialism into which much of decolonial critique has fallen. Secondly, this examination hopes to shed light on a critical and dialogical re-evaluation of love, on how trade and racial domination codes of white supremacy hold on love as an impossibility. It thus places it at the heart of a renewed decolonial revolution, which sees in antagonism - the inextinguishable conflict that follows the encounter with difference - the only possible rescue of democracy, but, above all, of 
a true and even paradoxical alliance between those whom the White body has brought to the limit of oppression and apparent segmentation. Ultimately, this reminds us that revolutionary love is the only one that, today helps restore the idea of free will as an inherently combative process.

Keywords: Love; Antagonism; White Body; Decolonial critique; Politics; Free will.

\section{O impossível muito além do corpo Branco: sobre amor, política e crítica descolonial}

\section{Resumo}

Este artigo tem dois objetivos. Por um lado, trata-se de examinar criticamente as chaves - que podem ser compreendidas como os "privilégios", os excessos, mas também os esgotamentos - do projeto moderno-colonial por meio do que Houria Bouteldja chama de corpo Branco, ou seja, a representação da transformação civilizatória avassaladora do Ocidente, mas também, por outro lado, do essencialismo antissistêmico em que uma boa parte da crítica descolonial caiu. Em segundo lugar, esta análise está enfocada em fazer uma reavaliação crítica e dialógica do amor, sobre a impossibilidade imposta a ele pelo circuito mercantil e os códigos de dominação raciais da supremacia branca. Desta forma, localiza-o no coração de uma renovada revolução descolonial, que vê no antagonismo - o conflito inextinguível que segue em direção à diferença - o único resgate possível da democracia, mas, acima de tudo, de uma verdadeiro e até mesmo paradoxal, aliança entre aqueles que o corpo Branco levou ao limite da opressão e da aparente segmentação. Isso nos faz lembrar, finalmente, que o amor revolucionário é o único que, hoje em dia, ajuda a restaurar a ideia de vontade como um processo essencialmente combativo.

Palavras-chave: Amor; Antagonismo; Corpo Branco; Crítica descolonial; Política; Livre arbítrio. 


\section{¿Qué es el cuerpo Blanco?}

Pero nosotros tenemos en común el

no constituir los cuerpos legítimos de

la nación.

Houria Bouteldja

La ambigüedad del proyecto moderno-colonial está inscrita en el cuerpo y la mente, y se ha internalizado su delirio. Por un lado, el proyecto de expansión y asimilación de sus valores, que de la franca opresión pasa al no menos violento discurso sobre la igualdad, se convierte, sobre todo, en un monumental esfuerzo mimético de saneamiento mental, existencial, político y epistémico. Por otro lado, la lógica de dicho proyecto solo puede operar sobre la construcción de ecodeterminantes ${ }^{1}$, es decir, sobre la identificación de rasgos de pertenencia a un lugar o creencia con el único fin de señalar la superioridad o prescindibilidad de otros, desplazándose entre nominaciones que, al menos en apariencia, parecen opuestas - es el peligroso vaivén entre el "nativo", el "local" o el "indígena", y el "migrante", el "extranjero" o el "colono"-. Hemos sido arrojados al lugar imposible de la propia identificación a través de aquello que, a un mismo tiempo, nos señala como esencialmente "otros". He aquí el delirio, el espejismo que nos despoja de forma momentánea de toda calidad subjetiva a través de la subordinación; somos a través de la obediencia, pero, sobre todo, de la ambigüedad, porque en medio de la asimilación de estos valores, imperceptible casi, se despierta en nosotros aquel rasgo con el que la diferencia, nuestra diferencia, ha sido nombrada. Es aquel instante en el

\footnotetext{
${ }^{1}$ La noción de ecodeterminantes ha sido ampliamente desarrollada por la crítica al proyecto moderno-colonial, en particular desde la perspectiva africana, para señalar lo que podríamos denominar las implicaciones éticas frente al estudio y la aprehensión de epistemologías otras -en un nivel teórico más que práctico-. Esto sirve para vitalizar la controversia, en palabras del filósofo africano Dismas A. Masolo (2017), "sobre si las disciplinas académicas se definen solo internamente, por las estructuras teóricas de sus contenidos [...] o si bien están influidas por condiciones externas" (p. 517).
}

Hallazgos

ISSN: 1794-3841 | e-ISSN: 2422-409X | DOI: https://doi.org/10.15332/2422409X

Vol. 18 N.0 36| julio-diciembre del 2021 
que, parafraseando a Jean Genet ${ }^{2}$, la búsqueda, la introspección, nos permite descubrir que en nuestro propio centro, en nuestro propio corazón, habita un Blanco que debe ser aniquilado. Se trata de una lógica que descubre su delirio, pues también opera en el sentido contrario -en el corazón Blanco, diríamos, también habita un "otro" cuya permanencia obliga su extinción-.

De cualquier forma, la distorsión de nuestro propio centro alcanza el colmo en la medida en que la insatisfacción conduce nuestros cuerpos y mentes, cuando descubrimos que nuestro corazón ha sido por siempre allanado por un "otro" que, eso creemos, no nos pertenece. Genet lo sabe, por eso su afirmación es más bien una súplica: aniquilar al Blanco que nos habita es aniquilar al Blanco que habita en su propio centro. Aniquilar la apariencia, la ambigüedad del proyecto moderno-colonial, eso nos pide. Acabar con el fingimiento de los ecodeterminantes, del "yo soy" que el encuentro con la diferencia despierta. Por eso diremos que el cuerpo Blanco es un cuerpo imaginado, pues no existe más que como superficie, como símbolo de una ficción: la pureza imposible que tiñe, en sus extremos, a todo encuentro, a toda empresa colonizadora - es el fanatismo de la blanquitud, epistemicida y depredador, pero también del esencialismo que reniega de él y al hacerlo se repliega en el microcosmos de la armonía ${ }^{3}-$.

\footnotetext{
${ }^{2}$ En su prefacio al libro Los hermanos de soledad, de George Jackson, Jean Genet exalta el poder revolucionario y reivindicativo del Black Panther Party en la búsqueda y reconocimiento, justamente, del blanco que habita en nuestro propio centro, un movimiento que permite resignificar el sentido del amor a los propios, pero, también, brindar al blanco la posibilidad de salvarse a sí mismo, un movimiento que es, a un mismo tiempo, "un arma de liberación y un poema de amor" (Genet, 2018, p. 9). ${ }^{3}$ Sobre este punto se volverá más adelante; sin embargo, conviene decir que la idea de una "armonía preestablecida" ha configurado no solo al cuerpo Blanco, sino también a buena parte de la crítica descolonial, lo que ha convertido todo sistema de relaciones, de sociabilidad, en un sistema cerrado y, en consecuencia, estéril. A propósito de este tema, Ernesto Laclau (1996) señala: "Aceptemos por un momento la posibilidad de que la armonía prestablecida fuera posible. En tal caso, los varios particularismos no estarían en una relación antagónica entre sí sino que coexistirían en
} 
Lo que hay de seductor en el cuerpo Blanco es, entonces, su ficción; el hechizo de una promesa; el actuar como si-como si fuéramos los primeros, los únicos, los merecedores, en razón de una histórica subordinación o una peligrosa proliferación, de un renovado respeto-. Un como si que al despojarnos parcialmente, ya se ha dicho, de toda calidad subjetiva, nos seduce con su anonimato, pues Occidente "siempre ha privilegiado el mito del Ego no situado" (Grosfoguel, 2016, p. 376), de la voz que nombra desde las sombras y al hacerlo nos borra del análisis. Así

Al desvincular la ubicación étnica/racial/de género/sexual - a través, diríamos, de ecodeterminantes - del sujeto hablante, la filosofía y las ciencias occidentales pueden producir un mito sobre un conocimiento universal fidedigno que encubre quién habla, así como su ubicación epistémica geopolítica y corpo-política en las estructuras del poder/conocimiento coloniales desde las cuales habla. (Grosfoguel, 2016, p. 376)

El cuerpo Blanco, como imaginado, es imposible de ubicar, universalizante en su mismidad. A falta de un rostro, o mejor, celebrando el hecho de una desproporción totalizante, ha conseguido escapar de su responsabilidad, este es el hechizo que constituye lo que Houria Bouteldja llama el sistema inmunitario blanco, la promesa de una absolución que hoy se esconde bajo los discursos sobre la igualdad y la inocencia, "ahí reside su última victoria, haber logrado exonerarse de toda culpa" (Bouteldja, 2017a, p. 43). Dicho de otra forma, el anonimato y la maleabilidad del cuerpo Blanco han dado paso al discurso en el que todo es reducible al consenso, al ánimo totalizante que se esconde bajo una única consigna: "todos somos iguales" - es el "relativismo" que intenta borrar los privilegios de la blanquitud,

una totalidad coherente. Esta hipótesis muestra claramente por qué el particularismo puro es, en última instancia, contradictorio" (pp. 54-55).

Hallazgos

ISSN: 1794-3841 | e-ISSN: 2422-409X | DOI: https://doi.org/10.15332/2422409X

Vol. 18 N.0 36| julio-diciembre del 2021 
cuando no el "universalismo" de sus valores, que solo justifica las dinámicas jerarquizantes entre los individuos-.

El sistema inmunitario blanco, delirante, se convierte, entonces, en una estrategia de evasión, cuyo horizonte de sentido renueva constantemente la idea de "pueblos con problemas" - "el problema judío", "el problema indio", “el problema negro", "el problema musulmán”, por ejemplo-, reduciendo toda diferencia, léase, toda calidad subjetiva, a la mismidad del pensamiento blanco, pues "reducido el contexto social e histórico a algo irrelevante [la traducción de "pueblos con problemas" en "pueblosobstáculo"], desaparece la posibilidad de encontrar matizaciones o inventar alternativas, convirtiéndose [el cuerpo Blanco en su maleabilidad] en una ideología radialmente exitosa" (Monedero, 2017, p. 200). Un éxito que, paradójicamente, anuncia ya su fracaso, pues busca perpetuarse a costa de la tensión constante e inevitable que es la vida misma, a la conflictualidad inherente a la experiencia del encuentro con la diferencia -con el judío, el indio, el negro o el musulmán-.

El espíritu expansionista que moviliza al cuerpo Blanco, informe en su defensa de la "igualdad", bien puede convertirse, entonces, en la oportunidad de inventar nuevos territorios.

El territorio de nuestros opresores es movedizo. Cuando la nación se desangra, ellos inventan Europa, y cuando Europa se desangra, ellos encuentran refugio en la blanquitud cristiana, que sirve como geografía política [...]. Si hubiese que imitar a los Blancos, la oportunidad es ahora o nunca para desplegarse más allá de las fronteras de la Nación e ir a buscar nuestras solidaridades. (Bouteldja, 2017a, p. 105)

Paradójicamente, el exceso que el cuerpo Blanco comporta - la pretensión de producir un conocimiento totalizador - se ha vuelto en su contra. Aquella "ideología radicalmente exitosa" comienza a apagarse en el 
instante en el que los cuerpos que produce, marcados por la prescindibilidad con la que son nombrados, hacen suyo el principio con el que se les quiso eliminar: la expansión. Aquellos cuerpos, atomizados en razón de una violenta segregación, han inventado un territorio; su geografía política, si cabe la expresión, reposa en la lucha que le sigue a la subordinación. Así, sostiene Bouteldja, aparece un nuevo fenómeno: "la

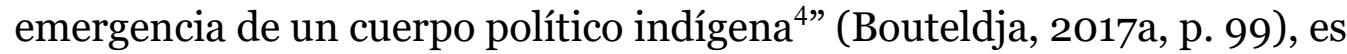
decir, una identidad otra, que aunque signada por la diferencia - "el negro", "el indio", "el judío" o "el musulmán”- no se constituye en términos esencialistas o culturalistas, sino políticos. Hablamos de la emergencia y consolidación, a pesar del cuerpo Blanco -o gracias a este-, de un sujeto que no puede ser definido en razón de sus propiedades identitarias y que excede, en consecuencia, las redes del particularismo y el universalismo - rostros del delirio Blanco-, perfilando así lo que Giorgio Agamben llama una "comunidad cualsea5", inesencial y abierta, tan extensa como lo han sido los mecanismos del sistema inmunitario blanco, privando al concepto de identidad de toda trascendencia y homogeneidad. El cuerpo Blanco - su ideal abstracto y movedizo sobre el "progreso" y la "igualdad" - ha terminado por fortalecer, así, lo que Ramón Grosfoguel (2017) llama "complicidad subversiva" (p. 394): una alianza comunitaria, igualmente inlocalizable, que excede el sentido tradicional del

\footnotetext{
${ }^{4}$ Vale la pena aclarar que el uso que Bouteldja hace del término indígena no es sinónimo, como podría pensarse, de pueblos originarios, sino que alude a la expresión con la cual el imperio francés nombraba a todos los pueblos dominados y explotados por sus colonias, expresión de la que se siguen las segregacionistas leyes del "indigenato". Así, el término indígena podría traducirse, como bien lo apunta Ramón Grosfoguel, como "sujetos coloniales" o "sujetos colonizados".

${ }^{5}$ En su texto, La comunidad que viene, Giorgio Agamben (1996) caracteriza dicha comunidad en los términos del ser cualsea, es decir, en los del libre movimiento de las singularidades, sin que estas lleguen a sobreponerse unas sobre otras, condicionándolas: "El cualsea que está aquí en cuestión no toma, desde luego, la singularidad en su indiferencia respecto a una propiedad común (a un concepto, por ejemplo: ser rojo, francés, musulmán), sino sólo en su ser tal cual es. Con ello, la singularidad se desprende del falso dilema que obliga al conocimiento a elegir entre la inefabilidad del individuo y la inteligibilidad del universal" (p. 9).
}

Hallazgos

ISSN: 1794-3841 | e-ISSN: 2422-409X | DOI: https://doi.org/10.15332/2422409X

Vol. 18 N.o 36| julio-diciembre del 2021 
conocimiento híbrido o el sincretismo, haciendo del conflicto, y la lucha que le sigue, un nuevo territorio. Es este, y no otro, el sentido de la búsqueda de nuevas solidaridades que rebasen las fronteras de la nación. “¿Y si nos aprovechamos del racismo para inventar territorios políticos nuevos?, ¿y si nos aprovechamos del fracaso de la integración [de la "igualdad"]?" (Bouteldja, 2017a, p. 105). Aquí nos confronta Bouteldja, a lo que agregaríamos: ¿y si allanamos el delirio Blanco para hacer de la diferencia una proposición existencial, la de asumir un punto de vista descentralizado? Entonces, tal vez, nos encontraríamos con una única respuesta: el viraje del "Yo pienso", del ego conquiro occidentalizado, al nosotros de una identidad política irreductible. Una única respuesta para la que, dirá Bouteldja, "solo hay un medio: el amor revolucionario" (Bouteldja, 2017a, p. 33).

\section{El cuerpo Blanco es un cuerpo triste}

[...] porque no hay terror que no tenga como base una especie de tristeza colectiva.

Gilles Deleuze

El cuerpo Blanco se presenta ante nosotros para recordarnos, a pesar suyo, la falibilidad de su mismidad; de una ilusoria disolución de la calidad subjetiva en el marco unitario de su cuerpo expandido, totalizante. Perversa cristalización del "Yo pienso", del Uno de cogito, que en su afán adhiere para sí toda diferencia. Por eso, diremos, el cuerpo Blanco es solo uno o no será; es la masa indiferenciada del proyecto civilizatorio. La esclavitud tiránica del cuerpo Blanco, que se traduce en una especie de saturación del Yo - de un individualismo exacerbado-, le impide dejar un lugar a los demás, “[...] ahí la tristeza de ser solo para uno mismo, condenado a acosar por todas partes el propio reflejo" (Bruckner, 2011, 
p. 77). Es la tristeza del cuerpo Blanco la que grita, entonces, cuando se nos dice "todos somos iguales".

Su tristeza merma parcialmente nuestra capacidad de componer relaciones, definiéndose -y definiéndonos - como el simple "propietario de su propia persona o de sus capacidades, sin que deba nada por ellas a la sociedad" (MacPherson, 2005, pp. 16-17). Volcándonos sobre nosotros mismos, el cuerpo Blanco trama su incapacidad: la carencia real del otro, encarnada, por ejemplo, en la figura del individuo mediatizado, del "hombre endeudado" que, de cualquier forma, comienza a asumir la condición de "empresario de sí mismo", y al hacerlo, transforma la desobediencia, que en ocasiones no es más que el asomo de su calidad subjetiva, en "responsabilidad" y miedo. Paradójicamente, esta carencia es también el canal de acceso a lo que Bouteldja llama amor revolucionario, una suerte de redescubrimiento y afirmación que, similar a la "lógica ecodeterminante”, opera por vías negativas. Sí, el cuerpo Blanco, su tristeza, termina por conjurar una alteridad radicalmente opuesta, imposible de contener, y para la cual solo existe una palabra: amor, pero no aquel que se inserta en el circuito mercantil o en los códigos de dominación, sino en el lugar de una salida revolucionaria.

La tristeza y el amor, o mejor, las políticas de la tristeza y las políticas del amor, son las expresiones inmediatas de las pasiones que, en el lenguaje spinozista, aumentan o disminuyen nuestro conatus, nuestra capacidad de

\footnotetext{
${ }^{6}$ Lazzarato (2013) señala, como condición del poder neoliberal, la condición de ser "empresario de sí mismo" como lógica de incorporación del "Acreedor Universal" (el capital) o, como aquí se presenta, la lógica avasallante del discurso sobre la autonomía y la igualdad, lo que supone la angustia permanente de vivir bajo el fracaso, cuando no la sublimación de la desobediencia en responsabilidad y miedo. En esta medida "el hombre endeudado" no sería otra cosa que un rostro posible de la mismidad del cuerpo Blanco bajo la forma del Gran Acreedor, pues "la relación entre acreedor y deudor [...] refuerza los mecanismos de explotación y dominación de manera transversal porque no hace distinción alguna entre trabajadores y desempleados, consumidores y productores, activos e inactivos [...]. Todos son 'deudores', culpables y responsables" (Lazzarato, 2013, p. 9).
} 
secundar la vida, de ser y obrar gracias a los otros o a pesar de ellos. La distinción entre unas y otras -entre las pasiones tristes y las pasiones alegres, dirá Spinoza - no solo desmiente la común idea según la cual la política se construye en ausencia de las pasiones - trasunto de las realidades concretas en el discurso técnico donde todo es reducible al consenso-, sino que, al hacerlo, manifiesta su necesidad, en otras palabras, el hecho de que la política siempre usa las pasiones ${ }^{7}$. En esta medida el individuo no podrá definirse como un "animal racional" -lugar al que la blanquitud siempre nos arroja - sino como un "animal pasional" que solo a través de la asociación puede convertirse en racional, o lo que es lo mismo, solo entonces sabrá precisar de qué pasiones prescindir para aumentar su conatus. Así, y solo así, devendrá en multitud, porque:

Si dos simultáneamente se reúnen y unen sus fuerzas, conjuntamente pueden más, y consecuentemente tienen conjuntamente más derechos sobre la naturaleza, que uno y otro solos; y cuanto más hayan unido sus vínculos de este modo, tanto más todos simultáneamente tendrán más derechos. (Spinoza, 2011, p. 634)

A "la tristeza de ser solo para uno mismo", diremos, se opone la capacidad de cohesión entre los individuos que desean preservar la propia vida. Esta capacidad, sin embargo, jamás podrá leerse como sinónimo de unicidad, sino de lucha; la cohesión, este devenir multitud, es, ante todo, una composición de fuerzas cuyo único fin será impedir que la vida misma - nuestra calidad subjetiva - se extinga, de ahí que las pasiones alegres -y en esto Spinoza es claro- supongan un doble esfuerzo. En primer lugar, se

\footnotetext{
7 Piénsese, por ejemplo, cómo la actual política neoliberal traduce la inseguridad y el temor en capital comercial: "el capital del miedo puede transformarse en cualquier tipo de rentabilidad, ya sea económica o política [...] La ley y el orden, reducidos cada vez más a una mera promesa de seguridad personal, se han convertido en un argumento de venta importante en los programas políticos" (Bauman, 2007, pp. 22-23). Esta es la manifestación del sistema inmune blanco que más adelante se desarrollará con el nombre de política del amor asegurado.
}

Hallazgos

ISSN: 1794-3841 | e-ISSN: 2422-409X | DOI: https://doi.org/10.15332/2422409X

Vol. 18 N. ${ }^{\circ} 36 \mid$ julio-diciembre del 2021 
trata de "aprovechar el aumento de potencia que se produce cuando nos encontramos con un cuerpo que conviene con el nuestro" (Hoyos, 2018, p. 263), instante inicial en el que la alegría, en cuanto encuentro, es todavía pasiva. En segundo lugar, se trata de apropiarnos de dicha potencia, de prolongarla, justamente, a través de una composición de fuerzas, "que consiste en saber disponer nuestro cuerpo de tal manera que se produzca una suma entre su potencia y la del resto de cuerpos" (Hoyos, 2018, p. 263), entonces, al fin, se tratará de una alegría activa ${ }^{8}$.

Una juntanza entre los cuerpos que luchan: esto es el amor revolucionario que, como se ha dicho, solo cobra sentido en presencia de su contrario. Es el contrasentido aparente que entraña la afirmación de una "razón apasionada" o, en palabras de Bouteldja, la "alegría de la desesperanza" que tiene como consecuencia "[...] el Nosotros de la superación de la raza y de su abolición, el Nosotros de la nueva identidad política que deberemos inventar juntos, el Nosotros de la mayoría descolonial” (Bouteldja, 2017a, p. 121).

El Nosotros del amor revolucionario subvierte el orden de las identidades, o mejor, el ideal que sobre estas ha impuesto el cuerpo Blanco, pues se afirma en condiciones de existencia que no son reducibles a propiedades identitarias, cuyo grado de pertenencia, si se quiere, determina lo que Agamben (1996), volviendo sobre Spinoza, entiende como una comunidad inesencial, cualsea 9 ; una comunidad de "singularidades que existen a su

\footnotetext{
${ }^{8}$ Deleuze, en su libro En medio de Spinoza, ilustra claramente este segundo esfuerzo a través de una imagen, "saber nadar consiste en saber disponer mi cuerpo para que su movimiento se componga con el movimiento de la ola, en lugar de descomponerse" (Deleuze, 2008, pp. 306-307). Se trata de un cuerpo que hace suyo el movimiento inevitable del encuentro con la diferencia, en esto consiste devenir lo más activos -felices- que podamos.

${ }^{9}$ En su texto, La comunidad que viene, Agamben vuelve sobre Spinoza para hablar de una comunidad cualsea como el opuesto de una comunidad de hombres solos, ya que no alude a la esencia o a cuestiones de este tipo, "cualsea es la cosa con todas sus propiedades, ninguna de las cuales constituye, empero, diferencia. La in-diferencia respecto a las propiedades es lo que individualiza" (Agamben, 1996, p. 18).
}

Hallazgos

ISSN: 1794-3841 | e-ISSN: 2422-409X | DOI: https://doi.org/10.15332/2422409X 
propia manera" (p. 18), inapropiables para el Estado y, en consecuencia, difícilmente manejables por el poder - es decir, no traducibles al discurso abstracto sobre la igualdad, como es el caso de los ecodeterminantes -, de ahí su condición de necesariamente hostiles o conflictivas, pues el oponerse, como derivado del no pertenecer a una mismidad, se convierte en una manera de relacionarse. Lo común, diremos, es aquello que se opone.

El carácter subversivo del amor, frente a una política de la tristeza, crea la existencia de lo común, un afecto activo, en términos spinozistas, que deviene en alianza libre. Negri (2000), sobre quien se volverá más adelante, destaca este carácter como el poder y el gobierno de la multitud, o, en otras palabras, al amor como pasión alegre y activa, que

[...] nos demuestra que la consistencia ontológica de los individuos y de la multitud permiten mirar al frente, a toda emergencia singular de vida como acto de resistencia y de creación [y al amor] como la pasión más fuerte que crea la existencia de lo común y destruye el mundo del poder. (p. 143)

El amor es una denuncia y su "anomalía" reside en su defensa del Nosotros de una nueva identidad - descolonial - en el seno del proyecto civilizatorio blanco: la Modernidad. La blanquitud y su civilización moderna, occidental y delirante han volcado la negatividad de sus propios afectos en el terror, traducible en los discursos y las políticas de seguridad que pesan sobre el otro de la diferencia; un terror que también amalgama y se ve representado en la tristeza de ser siempre para uno mismo. Ahí está la dificultad para el cuerpo Blanco de asumir el amor en condiciones que no sean las de la amenaza latente y la pérdida irremediable: la amenaza de un otro cuya diferencia es la pérdida de la propia razón. Por eso, continúa Negri (2000): “[...] a los filósofos no les gusta la palabra amor $-\mathrm{y}$ los posmodernos la conjugan con el marchitarse del deseo-" (p. 143). 
El otro, que a estas alturas parece ser cualquiera, representa el vínculo insoportable de la propia afirmación a través de su opuesto - es el "yo soy" abstracto que se levanta sobre lo que es leído en otro como una carencia ${ }^{10}$ - . Entonces, diremos que resulta patente que el cuerpo Blanco necesite tanto lo que destruye como lo que afirma, una suerte de desdoblamiento que encarna a los dos enemigos de un Nosotros del amor revolucionario: la fiabilidad del aseguramiento y la lógica del goce personal, del disfrute ilimitado de uno mismo. Seguridad y bienestar como ordenanzas del sistema inmunitario blanco, que escapa de su responsabilidad histórica al hacernos creer que

Si el otro sufre, es asunto suyo, ¿no es verdad? Eso no pertenece a la modernidad. De la misma manera que los "cero muertos" para los militares occidentales. Las bombas que ellos lanzan matan a gran cantidad de personas que son culpables de vivir justo debajo. Son afganos, palestinos... [de cualquier forma, "pueblos con problemas"]. Tampoco ellos son modernos. El amor asegurado, como todo aquello que se basa en la seguridad, es la ausencia de riesgo [...]. (Badiou, 2011, p. 21)

Tal vez ninguna idea, como la del amor asegurado, ejemplifique mejor la tristeza del cuerpo Blanco y su desarrollo, que va siempre de la diferencia a la mismidad. Una tristeza que, puesta al servicio de la trascendencia ${ }^{11}$, consigue desviar nuestra atención del problema fundamental que supone el encuentro con el otro, pues “[...] lo constitutivo no es el problema de la

\footnotetext{
${ }^{10}$ Cabe señalar que la idea de "pueblos con problemas" se acompaña de un reiterativo discurso sobre la carencia; así, la idea del "problema indio" o el "problema negro", por ejemplo, se ha obligado a transitar, históricamente, por el camino de los "pueblos sin escritura", los "pueblos sin historia", los "pueblos sin desarrollo" y, más recientemente, los "pueblos sin democracia", alimentando la retórica de la Modernidad que habla del salvar al otro de sus propias atrocidades.

${ }^{11}$ Desde este punto de vista, es siempre una figura abstracta-transcendental la que ha conducido al cuerpo Blanco. Bien sea bajo la forma de las grandes dictaduras o las grandes religiones, esta figura responde a la sacralización de la voluntad -la voluntad del pueblo o la voluntad de Dios, por ejemplo- como manifestación de las pasiones que gobiernan la política y desestiman la responsabilidad histórica y particular de los sujetos.
}

Hallazgos

ISSN: 1794-3841 | e-ISSN: 2422-409X | DOI: https://doi.org/10.15332/2422409X

Vol. 18 N.o 36| julio-diciembre del 2021 
diferencia. La diferencia es lo que hay. Las personas, las naciones, son forzosamente diferentes. El problema radica en saber cómo se produce lo mismo" (Badiou, 2013, p. 61), en cuestionar, diríamos, la relación entre la sutil expansión de un único cuerpo - el Blanco - y la idea abstracta de bienestar e identidad que, incluso a pesar de nosotros mismos, nos funde con él.

El amor asegurado ocupa así el lugar imposible de la salvaguarda ante el otro, del temor que conduce su necesidad. El cuerpo Blanco es un cuerpo triste, justamente, porque intenta pasar por alto el riesgo que dinamiza lo que hay de constitutivo entre las gentes y lo traduce en problema. Triste, sobre todo, porque emprende la tarea inútil de reducir los cuerpos de la diferencia a una singularidad apropiable y, en consecuencia, susceptible de ser manejada por el poder - ser negro, ser indio, ser feminista, ser de izquierdas, ser afgano o palestino, etc. - . Triste, siempre que intenta disciplinar estas alteridades, construyendo un mundo común, totalizante. El cuerpo Blanco frustra todo encuentro o, en el mejor de los casos, lo asume como la simple suma de las partes -aquella saturación del Yo, del uno acosado a ver su propio reflejo en todas partes-, por eso jamás llega a convertirse en "alegría activa" que es, si cabe la expresión, otro nombre para el infinito del amor revolucionario, infinito que, en tanto es inesencial, es inapropiable. Porque "el amor [en este sentido] es abordar al $\operatorname{ser}^{12}$ ", no a lo que hay en él de parcial y localizable, y hacerse cargo de su infinidad: "Sí, porque de otro modo el amor sería solo el encuentro, y si es solo el encuentro, pronto tendremos el regreso de la concepción pesimista"

\footnotetext{
${ }^{12}$ Badiou (2013) recurre con frecuencia a la fórmula de Lacan "El amor es abordar al ser" (aparecida al final de la última lección de su seminario Aun) para señalar la diferencia entre el amor y el deseo, siendo este último siempre parcial, "[...] alojado en algún punto del cuerpo del otro" (p. 91). Lectura que le permite abordar la aparente imposibilidad del amor en una sociedad marcada por el "deseo de consumo".
}

Hallazgos

ISSN: 1794-3841 | e-ISSN: 2422-409X | DOI: https://doi.org/10.15332/2422409X

Vol. 18 N.0 36| julio-diciembre del 2021 
(Badiou, 2008, p. 108) de la tristeza que mantiene toda potencia en un estado de pasividad.

Por eso el Nosotros del amor revolucionario, diremos, se hace cargo del infinito, responsable de las contradicciones y la indeterminación que le siguen y que el amor asegurado intenta, a toda costa, uniformizar porque le teme. De ahí su constante conversión del desacuerdo y la diferencia en consenso y disciplina. Un Nosotros que se opone abiertamente al sujeto de la blanquitud, cuyo proceso implica la superposición de capas y capas de "yoes"13 egoístas y posesivos; un acorazamiento que evita el contagio del otro. Así, el amor asegurado pasa a ocupar el lugar de la carencia - del otro- y del miedo - a su diferencia-, de la ausencia de riesgo que, como política de la tristeza, anula la conciencia que nace de la experimentación del conflicto.

\section{El antagonismo como límite conjunto entre el amor y la política}

El sujeto político no es, sino que siempre está siendo y está siendo porque siempre está luchando.

Massimo Modonesi

En un texto titulado La rivalidad homérica, Nietzsche señala el valor agonal de los griegos como aquella disposición a la lucha que mantiene siempre en alto la vitalidad de la polis; un impulso conflictual, diríamos, cuyo dinamismo termina por expulsar a cualquiera que haga uso de una autoridad absoluta sobre otros. De otra forma, “[...] se agotaría la rivalidad

\footnotetext{
${ }^{13}$ Esta lógica de superposición opera, también, como un mecanismo jerarquizante en la relación sujeto-Estado, y se convierte, extrañamente, en un dispositivo de control y socialización, en "una práctica social (y retórica), largamente aceptada en estos tiempos, la de la creación de instancias de control que se acumulan unas sobre otras" (Costa Matos, 2015, p. 188). Con esto señala Costa Matos que esta superposición es el verdadero rostro de la operatividad del poder asociado al progreso.
}

Hallazgos

ISSN: 1794-3841 | e-ISSN: 2422-409X | DOI: https://doi.org/10.15332/2422409X

Vol. 18 N. ${ }^{\circ} 36 \mid$ julio-diciembre del 2021 
y estaría en peligro el eterno fundamento de vida del Estado [...] al único que descuella, se le aparta, para que de nuevo despierte el juego antagónico de las fuerzas" (Nietzsche, 2010, p. 46). Solo a través de la aceptación plena de la rivalidad, es decir, del conflicto que le sigue al encuentro, es posible retornar a la política su condición de inapropiabilidad, de renovación constante. La voluntad de lucha, como “eterno fundamento de vida del Estado" es, en este sentido, trágica, que no triste - este sería el peligroso retorno de la pasividad blanca-.

Esto quiere decir que todas las formas de sociabilidad -incluida la del cuerpo Blanco- están atravesadas por la voluntad de aumentar su potencia. Este es el sentido de un encuentro entre las fuerzas que solo dejará atrás el estado de pasividad - es decir, el estatismo de la uniformidad - cuando dicho encuentro se convierta en un estado continuo. Entonces, y solo entonces, se descubrirá ante nosotros "el juego antagónico". Este es el valor activo del impulso antagónico - el de un presente, el encuentro, que se renueva constantemente-, de lo que se desprende que un sujeto antagónico es aquel que se configura en el conflicto.

El retorno a la tragedia como valor activo señala la imposibilidad de una sociedad cerrada, como una mismidad totalizante, al tiempo que redefine las ideas de autonomía y libertad, no ya como la promesa de alcanzar el lugar de aquel que impone su autoridad o, en el mejor de los casos, como estado esencial, sino como el poder, precisamente, de estar en su contra, pues

antes que hablar de una libertad esencial sería mejor hablar de un “agonismo", de una relación que es al mismo tiempo recíproca incitación y lucha; menos una confrontación cara a cara que paraliza a ambos lados, 
que una permanente provocación ${ }^{14}$. (Foucault citado en Castro-Gómez, 2017, p. 239)

Foucault, lector de Nietzsche, lleva así el valor agonístico a las instancias del poder, donde lo constitutivo de la experiencia humana es, precisamente, el choque entre las fuerzas. La voluntad, como proceso esencialmente combativo, guiaría, entonces, el ejercicio de la libertad, puesta en el lugar de la "permanente provocación", de lo que se sigue, en otras palabras, que el sujeto antagónico es, por definición, libre, de ahí el abandono de cualquier modelo bélico - explícito en Foucault-, del uso de una autoridad absoluta. De otra forma nos encontraríamos con el retorno de la tristeza que antecede toda dominación, pues la condición misma del juego antagónico es la rivalidad, no la opresión.

A través de esta visión se comprende, entonces, que el antagonismo jamás podrá ser eliminado, que su condición de permanencia, muy a pesar de las tendencias progresistas y lineales de la mismidad, crea una comunidad que existe ya y desde siempre. Por eso, diremos, el antagonismo representa la infinidad de la diferencia. Una dimensión de presente continuo, del hacerse responsable del conflicto, de la diferencia que dinamiza el choque entre las fuerzas; una dimensión que perfila ya lo que podríamos llamar una construcción amorosa.

El antagonismo es una potencia disimétrica, infinita, que de ninguna manera podrá definirse en oposición a lo finito, es decir, al sentido unidireccional, aunque extenso, que conduce al cuerpo Blanco -siempre

\footnotetext{
${ }^{14}$ Santiago Castro-Gómez (2017) rescata la lectura foucaultiana de la dimensión ontológica del poder para señalar el enfrentamiento entre las fuerzas como un ejercicio fundamentalmente antagónico, es decir, como instancia de gobierno antes que de dominación cuando el sometimiento no conduce al enfrentamiento entre una voluntad y otra, hecho que restringiría el ejercicio de la libertad. "El ejercicio del gobierno, por el contrario, supone dejar actuar al adversario, permitirle ejecutar sus jugadas estratégicas de incitación y provocación. Y cuando a través de esas jugadas el adversario consigue desgobernarse, superar los límites que le ha impuesto la hegemonía, entonces el juego comenzará de nuevo" (p. 239).
}

Hallazgos

ISSN: 1794-3841 | e-ISSN: 2422-409X | DOI: https://doi.org/10.15332/2422409X 
consensual-y su firme promesa sobre el futuro, sobre el llegar a ser. El antagonismo siempre está siendo y en esta medida fractura la lógica de la superposición, del relacionamiento vertical y jerarquizante, pues necesita del otro en los términos de su libertad. Este estar siendo siempre es el que define la emergencia de un Nosotros en el sentido que le da Bouteldja, ya que este se conjura allí donde las singularidades no sufren reducción alguna, donde, como se ha dicho antes, lo común es lo que se opone.

[...] ahí donde podrían aniquilarse las razas y donde podría encararse nuestra igual dignidad. Como cedo al sentimentalismo me pregunto si no está ahí el lugar del amor. Del amor revolucionario. Las almas románticas dirán que el amor es siempre desinteresado. Pero precisamente por eso, ¿cómo encarar el amor entre nosotros si los privilegios de unos descansan sobre la opresión de los otros? (Bouteldja, 2017a, p. 48)

El amor deviene revolucionario siempre que fracture la unidad narcisista de cada cual, es decir, siempre que el Nosotros le sobreviva al cuerpo Blanco, unitario, y le sobrevive si, y solo si, hace suya la renovación del “juego antagónico". Este es el sentido tras la pregunta de Bouteldja. Así, la voluntad de lucha - la rivalidad misma - termina por allanar un punto de imposibilidad -el llegar a ser de la blanquitud, que parece decirnos que fuera de sus límites los seres ocupan el lugar de lo indescifrable, el de "pueblos con problemas", reducidos a ser habitantes de la "zona del no$\operatorname{ser}^{15 "}-$, de tal manera que se vuelva posible. Dicho de otra forma, la

\footnotetext{
15 La Modernidad define un límite infranqueable que el cuerpo Blanco representa, una frontera, si se quiere, que determina los criterios de pertenencia a este cuerpo unitario -recuérdese, por ejemplo, la función clasificatoria de los ecodeterminantes-. De este modo, aquellos que habitan del "otro lado" se les arrebata la condición de humanidad. Este límite es el que Ramón Grosfoguel caracteriza a través de la "zona del ser" y la "zona del no-ser". "Dado que la humanidad de la gente clasificada en la zona del noser no es reconocida, dado que son tratados como no-humanos o subhumanos, es decir, sin normas de derecho y civilidad, entonces se permiten actos de violencia, violaciones y apropiaciones que en la zona del ser serían inaceptables" (Grosfoguel, 2011, p. 101).
}

Hallazgos

ISSN: 1794-3841 | e-ISSN: 2422-409X | DOI: https://doi.org/10.15332/2422409X

Vol. 18 N.0 36| julio-diciembre del 2021 
condición de posibilidad del Nosotros se encuentra, justamente, en su imposibilidad. El más allá del cuerpo Blanco, en cuanto “imposible”, es el amor revolucionario.

Lejos de ser una simple contradicción ${ }^{16}$, el antagonismo señala una disposición a actuar, una suerte de acumulación experiencial de una subjetividad que se afirma en el conflicto constante e inevitable que es la vida misma, de ahí que el sujeto antagónico, como acertadamente advierte Massimo Modonesi (2016), “[...] no destaca solo como unidad de combate [...] sino como punto de condensación de su experiencia [...] como portador y reproductor de emociones o de estructuras de sentimiento" (p. 94); una restitución, sin duda, de las pasiones que conducen la política, pero, sobre todo, de un desplazamiento antagónico, si cabe la expresión, que permite al conflicto, en cuanto experiencia, orbitar entre la esfera íntima - de la propia afirmación - y la pública - de construcción de lo común-. El sujeto antagónico encarna, en sí mismo, la ubicación liminal de la experiencia, de una reevaluación crítica, y constante, de la voluntad - como ejercicio de volición colectiva, pero también, y a un mismo tiempo, como cuestionamiento retrospectivo-.

A este lugar podríamos extender el sentido de la "permanente provocación", el de hacerse responsable del conflicto que le sucede a todo encuentro, que no solo pone en peligro el sentido unitario del cuerpo Blanco, sino que anuncia la emergencia de lo que Julia Kristeva llama una "cultura en re-vuelta", que

\footnotetext{
16 Propia, por ejemplo, de algunas corrientes del marxismo que asumen la contradicción como única dimensión de la relación trabajo-capital, perdiendo de vista, en palabras de John Holloway (1995) - a quien Modonesi se refiere constantemente-, "el conflicto más profundo - lógica y existencialmente anterior- [...]. Esta contradicción es un antagonismo social vivo, palpitante, la lucha constante e inevitable que es la vida misma" (p. 256).
} 
[...] explora la permanencia de la contradicción, de lo provisorio de la reconciliación, la evidencia de todo lo que pone a prueba la posibilidad del sentido unitario [...]. Esta re-vuelta no se realiza en el mundo de la acción, sino en el de la vida psíquica y en el de sus manifestaciones sociales [...]. Sin embargo, en la medida en que se trata de una mutación del vínculo del hombre con el sentido, esta re-vuelta cultural concierne intrínsecamente a la vida de la ciudad y tiene consecuencias profundamente políticas; plantea otra política, la de la conflictividad permanente. (Kristeva, 1999, pp. 24-25)

Esta otra política - la del Nosotros - tiene lugar siempre que vea la intimidad - la vida psíquica - como la necesidad de un vínculo que podría, eventualmente, sentar las bases de una nueva sociabilidad, tan extensa como inapropiable. El abandono del cuestionamiento retrospectivo indica, por el contrario, la gran estrategia de estabilidad, de reconciliación si se quiere, con los valores que el cuerpo Blanco representa - tales como el progreso y la igualdad-, un equilibrio que no puede ser más que ilusorio y totalitario. De ahí que nuestra experiencia social tanto como nuestra manera de pensar se reduzcan, en el mejor de los casos, al simple rechazo de lo antiguo y su posterior sustitución por nuevos dogmas ${ }^{17}$. Kristeva (1999) es clara: en una cultura en re-vuelta el ser se revela y asume una "actitud de libertad que adquiere el aspecto de la contestación política"; un retorno a la inquietud permanente, una "vuelta del pensamiento a la fuente [...] al cuerpo sensible ${ }^{18 ”}$ (p. 93).

\footnotetext{
${ }^{17} \mathrm{Al}$ inicio del texto El porvenir de la revuelta, Kristeva (1999) señala que lo que comúnmente se entiende como "revolución" o "revuelta" no es más que una apropiación nihilista por parte de la política stricto sensu, de la capacidad de cuestionamiento, "entendemos por nihilismo el rechazo de los antiguos valores en pos de un culto de nuevos valores sin interrogación"; en consecuencia, un "nihilista en seudo-revuelta es alguien que se ha reconciliado con la estabilidad de los nuevos valores" (p. 17).

${ }^{18}$ Cabe señalar que la referencia que Kristeva hace al "cuerpo sensible" viene de su lectura de Spinoza, del valor que este da, como se ha señalado anteriormente, a un género de conocimiento otro, aquel que responde al influjo de las pasiones.
}

Hallazgos

ISSN: 1794-3841 | e-ISSN: 2422-409X | DOI: https://doi.org/10.15332/2422409X

Vol. 18 N.o 36| julio-diciembre del 2021 
Frente al cuerpo Blanco, un cuerpo que, en cuanto sensible, es también inapropiable, pues sirve como lugar de tránsito y renovación de la experiencia y, en esta medida, como único ámbito posible del estar siendo siempre; una continuidad que solo el amor hace posible, pues, primero como intimidad, luego como revolución, se nos presenta como acontecimiento en sentido fuerte, es decir, como emergencia de una alteridad radical que nos obliga a cambiar, o mejor, a renovar, las coordenadas que hasta entonces nos orientaban en el mundo. El amor es, entonces, la re-vuelta, la condición misma del juego antagónico: proceso experiencial e interiorización del conflicto que impide que cualquier forma de dominación se totalice.

\title{
Ser a través del cuerpo Blanco, sobre el amor como política descolonial
}

\author{
La dignidad es saberse \\ responsable de uno, de diez, de \\ mil. Es nuestra capacidad de \\ amarnos y amar a ese Otro, a ese \\ irresponsable, a empujarlo e \\ impedir que su locura se \\ despliegue aún más y, con él, \\ salvar eso que queda por salvar \\ de este este pobre mundo.
}

Houria Bouteldja

Decir que todo cuerpo sensible es a través del cuerpo Blanco es reconocer, en ambos, una condición de intangibilidad permanente. En ambos casos se trata de un cuerpo que, en sentido estricto, no es sino que está siendo, o mejor, que se construye en función de su propio movimiento. Sin embargo, los términos de esta condición son en extremo opuestos: el cuerpo Blanco está siendo proporcionalmente a su expansión, a la adaptabilidad que 
asume con el único fin de adherir para sí la diferencia; por el contrario, todo cuerpo sensible está siendo en la medida en que, parafraseando a Deleuze, sabe disponerse para que su movimiento se componga con el movimiento de la ola, es decir, del encuentro inevitable con la diferencia. Mientras que el primero, para seguir con la imagen, bracea inútilmente, el segundo hace suyo el movimiento. El problema radica en saber distinguir la condición de intangibilidad entre uno y otro o, mejor, y para empezar, en reconocer hasta qué punto esta condición, en cuanto expansión, consigue envolver, incluso, a todo cuerpo sensible. La pregunta es, para volver sobre Genet, ¿qué ocurre cuando descubrimos que en nuestro propio centro habita un blanco?

En principio, la respuesta a esta pregunta, puesta en boca de la política blanca, pero también de la política descolonial, parece lanzarnos siempre ante las mismas dos opciones: por un lado, ceder a la identificación del cuerpo Blanco - a la lógica de ver el propio reflejo en todas partes-, de lo que se sigue, inevitablemente, un aumento en la fuerza del proyecto civilizatorio de la Modernidad, cuya adaptabilidad alcanza el colmo de lo que Bouteldja llama izquierda blanca, fecunda en actitudes condescendientes y paternalistas frente a la diferencia, sostenidas sobre la firme creencia en el "progreso", la "libertad", la "igualdad" o la "civilización", un "convertir sus luchas y demandas [las de la diferencia] en ingredientes de una reingeniería cultural y estatal capaz de someterlas a su voluntad neutralizadora" (Rivera Cusicanqui, 2011, p. 62). Por otro lado, se encuentra el abandono radical del cuerpo Blanco, sus valores y las instituciones que lo representan, atraídos - nostálgicos acaso- por la "espiritualidad telúrica" de aquellos saberes o movimientos que, al menos en principio, parecen haber escapado del proyecto civilizatorio de la Modernidad. 
Cualquiera que sea el camino, lo que se encuentra al final tiene un mismo y único nombre: la tristeza. La identificación tanto como el rechazo comparten la radicalidad de aquel que se repliega sobre sí mismo, que fractura todo encuentro y, al hacerlo, disminuye su potencia. De ahí que todo ejercicio político, por no decir que toda lucha, se limite a la identidad. Restringido a la singularidad concreta, el cuerpo Blanco, pero también el abyayalista $^{19}$, limita, o mejor, anula la emergencia de un Nosotros; la posibilidad misma de una pasión alegre, de la juntanza o, tal como lo ha denominado Butler (2017), de la alianza, que no es -al menos no únicamente, nos aclara- "una forma social del futuro" (p. 73), pues excede, diríamos con otras palabras, el llegar a ser de la blanquitud.

[...] en ocasiones se trata de algo latente, o incluso constituye la estructura verdadera de nuestra formación como sujetos, por ejemplo, cuando la alianza tiene lugar al interior de un solo sujeto, cuando es posible decir: "Yo mismo soy una alianza" [...]. Esta perspectiva, de la cual se deriva la relacionabilidad social en el pronombre de primera persona, nos obliga a captar la deficiencia de las ontologías identitarias [...]. Aquí no se trata de que yo sea un cúmulo de identidades, sino que soy de por sí una reunión, una asamblea. (Butler, 2017, p. 73)

Decir que todo cuerpo sensible es a través del cuerpo Blanco es permitir que la intangibilidad, como condición compartida, permita la salvación de ambos; solo entonces la voluntad que los moviliza abandonará el lugar de la mismidad, para dar paso a una "alianza de cuerpos distintos y adyacentes cuya acción e inacción exige un futuro distinto" (Butler, 2017,

\footnotetext{
19 En su libro El tonto y los canallas. Notas para un republicanismo trasnmoderno, Santiago Castro-Gómez (2019) caracteriza esta variante del pensamiento descolonial, que busca escapar a toda costa de la Modernidad recurriendo a las "epistemologías otras", que "no basan su conocimiento en la relación sujeto-objeto y que cultivan una 'espiritualidad telúrica' en relación de armonía con todos los seres vivos [...] - una especie de éxodo epistémico-político-para replegarse en el microcosmos orgánico de la vida comunitaria" (p. 11). El cuerpo abyayalista sería, siguiendo a Castro-Gómez, aquel que invoca a Abya Yala como exterioridad esencial frente a la Modernidad.
}

Hallazgos

ISSN: 1794-3841 | e-ISSN: 2422-409X | DOI: https://doi.org/10.15332/2422409X

Vol. 18 N.o 36| julio-diciembre del 2021 
p. 79); el tiempo renovado de la acción aliada, el de un infinito que sobrepasa, por mucho, "la tristeza de ser solo para uno mismo". Esto significa comprender que la salvación del otro no es más que la posibilidad de salvarse a sí mismo; aquel instante en el que, a la manera de Lévinas (2003), el ser del sí mismo - del Uno- se deshace en el ser de un otro por completo distinto, un "uno-para-el-otro”, afirmaría el filósofo, un tránsito que significa la "proximidad del Mismo con el Otro" (p. 212) - es decir, cuando la ya mencionada saturación del yo deviene en fraternidad-. Entonces el Infinito ${ }^{20}$ es, sin más, el imperativo del amor revolucionario.

Este amor, o sea, este reconocimiento de que la blanquitud es una construcción histórica [...]. Postula que la blanquitud es, al mismo tiempo, una herencia histórica nacida de la dominación de Occidente, pero también una elección política. En otras palabras, los blancos pueden escoger renunciar a su blanquitud [...]. Este acto de amor es un acto revolucionario que propone una alternativa radical a la guerra civil, a la violencia. (Bouteldja, 2017b, pp. 158-159)

Esta alternativa, como renuncia de cualquier modelo bélico del poder, pesa positivamente en lo que antes se ha señalado como la construcción de un sujeto antagónico. En primer lugar, porque del reconocimiento del cuerpo Blanco como construcción histórica y elección política se deriva la irrupción del conflicto como el terreno de las relaciones sociales alternativas y, por tanto, del restablecimiento y el ejercicio de un contrapoder; en segundo lugar, porque este reconocimiento es, también, el lugar de la "permanente provocación”, del tránsito de una lógica de la

\footnotetext{
20 Vale la pena mencionar que, en sentido lévinasiano, la idea de Infinito se asocia al tránsito del Yo al Otro. Dicho tránsito, en cuanto producción y no síntesis - proceso y no resultado, podríamos decir-, viene a resaltar lo que hay de inagotable en todo encuentro con la diferencia (en el sentido que aquí se ha venido desarrollando); un modo de ser/estar de lo Infinito que, en palabras de Lévinas (2003), "constituye un acontecimiento en el ser" (p. 77).
}

Hallazgos

ISSN: 1794-3841 | e-ISSN: 2422-409X | DOI: https://doi.org/10.15332/2422409X

Vol. 18 N. ${ }^{\circ} 36 \mid$ julio-diciembre del 2021 
dominación a una de la hegemonía ${ }^{21}$, es decir, de la lucha entre voluntades o agentes libres que busquen desarticular el orden establecido, y así renovar el "juego antagónico"; en tercer lugar, porque permite cruzar los límites que la blanquitud ha impuesto sobre lo público y lo privado a través del conflicto como experiencia, es la "[...] relacionabilidad social en el pronombre de primera persona" (Butler, 2017, p. 73), el reconocimiento de las pasiones que gobiernan la política y permiten liberarla del estatismo de la esfera pública-inescrutable -el congreso, el parlamento, el concilio, de cualquier forma, la habitación cerrada-, reafirmando así, como lo ha indicado Butler (2017), que "el verdadero espacio [de la política] está entonces entre la gente" (p. 77).

El delirio identitario blanco se nos muestra gracias a la alternativa radical que el amor representa, a la latencia de un Nosotros cuyo sentido se encuentra, primero, en la afectación mutua de los cuerpos que han sido dejados al margen. Así, aún antes de cualquier nominación, de cualquier clasificación, este Nosotros ya se ha formado, ha conseguido corporizar el conflicto como instancia trasversal de todo ejercicio público; es, pues, la dimensión fundante de la política ${ }^{22}$. Sin embargo, este amor, como inmanencia de un Nosotros, solo puede dejar atrás su condición pasiva, en cuanto latencia, siempre que devenga en amor revolucionario. Solo el acto de amor como acto revolucionario puede sentar las bases de un ser a

\footnotetext{
${ }^{21}$ Este movimiento es fundamental en la distinción que hace Ernesto Laclau (1996) entre universalismo y universalidad. El primero se refiere al gesto característico de la mismidad, y el segundo alude a la relación antagónica entre particularidades; "Porque si cada identidad está en una relación diferencial, no antagónica, con todas las demás identidades, la identidad en cuestión es puramente diferencial [...]" (pp. 54-55), es decir, pasiva, incapaz del giro hegemónico que allana el poder y hace que toda dominación sea inestable.

${ }^{22}$ La política, según Lefort, es el lugar de lo que podríamos llamar "representatividad vacía" o de lo público-inescrutable, es decir, de las prácticas y discursos que regulan los conflictos. Lo político, por el contrario, se ubica como instancia previa, refiere al "modo de ser" de la sociedad, ciertamente inestable, conflictual, y que, en consecuencia, no depende de ninguna de las prácticas de la política (la conformación de partidos, la formulación y ejecución de leyes, por ejemplo). Lo político es, entonces, la dimensión instituyente de todo ejercicio público (Lefort, 2004).
}

Hallazgos

ISSN: 1794-3841 | e-ISSN: 2422-409X | DOI: https://doi.org/10.15332/2422409X

Vol. 18 N.0 36| julio-diciembre del 2021 
través de o, parafraseando a Bouteldja, de la responsabilidad que se sigue de "amar a ese Otro".

El amor revolucionario se convierte así en giro hegemónico, en prevalencia de la lucha como condición de vida; en apertura al encuentro, pero sobre todo al diálogo transversal con la diferencia, es decir, en resignificacion de la exterioridad que, como se ha dicho, se mueve entre el rechazo y el ensimismamiento radical. Un amor que bien puede ocupar el lugar de renovación de lo que Enrique Dussel (2016) llama "transmodernidad", esa "radical novedad que significa la irrupción, como desde la nada, desde exterioridad alternativa de lo siempre distinto" (p. 283), pues indica un "momento de verdad" que podría servir para reformular críticamente al cuerpo Blanco como construcción histórica y elección política de la Modernidad, y ofrecer así las claves para su propia descolonización; una "afirmación de la exterioridad despreciada [como] novedad, desafío y subsunción de lo mejor de la misma Modernidad" (p. 294) a través del límite conjunto que el amor ofrece entre lo público y lo privado.

Asumir positivamente el lugar de la exterioridad despreciada es permitir la emergencia del Nosotros de una nueva identidad política, una que consiga ser a través de la tristeza del cuerpo Blanco y resignifique, incluso, su histórica vulneración. A esto se refiere Bouteldja cuando dice, a manera de provocación: “iFelices sean los agrietados, porque ellos dejarán pasar la luz!" (Bouteldja, 2017a, p. 19)

\section{Una invitación a la democracia como lazo amoroso}

Resulta difícil, contradictorio acaso, intentar una conclusión cuando lo que se ha querido es asumir el lugar del estar siendo siempre. Imposible cerrar aquello que, por definición, es la infinidad de la apertura. Mejor sería hablar, entonces, de una invitación. 
No existe una mejor manera de destruir la política que haciendo un uso eficiente de la tristeza que conduce al cuerpo Blanco. Esta es la que media, como se ha intentado señalar, en la eliminación de la función oblativa (del otro); esta, a su vez, no es otra cosa que el intento airado por eliminar la democracia - que en el mejor de los casos se ubica, en el universo de la blanquitud, como simple nominación, como herramienta de reiteración de la mismidad -. La experiencia del otro, de la diferencia, presupone una estructura performativa que puede, en sentido spinozista, ayudarnos a componer relaciones, tornándonos seres democráticos. En esta medida, y como rescate de lo que podríamos llamar una potencial composición de relaciones, el amor revolucionario es, esencialmente, producción simbólica, un generador de lenguaje, si se quiere, entre aquellos a los que les fue arrebatado, pero, también, con quienes pretendieron hacerlo; es, en definitiva, la posibilidad del diálogo como acontecimiento.

Es el sinónimo de democracia si la pensamos como lazo amoroso entre personas que pueden hablar y escucharse, no porque sean iguales, sino porque dejaron de lado sus caparazones de odio y derribaron el muro de hormigón en el que están enterradas sus subjetividades. (Tiburi, 2018, p. 38)

La tarea por venir no puede ser otra, siguiendo a Tiburi (2018), que la del "guerrero sutil que [...] desafía el poder desde su interioridad" (p. 46), esta re-vuelta íntima que el amor consigue. El diálogo, un diálogo amorosoacotencial, bien puede ser la metodología democrática que restituya esta sutileza en lo íntimo tanto como en lo público. Se trata de una tarea provocadora que exige, en primer lugar, un desarrollo mucho más extenso de lo que aquí se ha llamado la tristeza del cuerpo Blanco como dispositivo en sentido foucaultinao, es decir, como mecanismo de reproducción de modos de ser y actuar en sentido histórico, que muta según las condiciones de posibilidad en las que tiene lugar. Nos referimos aquí a la razón 
normativa que crea las condiciones de producción y legitimidad de un otro que es necesario anular con tanta cautela como intimidación. Esto llevaría, a un mismo tiempo, a la identificación de la morfología cambiante del cuerpo Blanco, de su condición acomodaticia -recuérdense, por ejemplo, los discursos sobre la igualdad y la libertad propios del sistema inmune blanco-. La tarea por venir, tan extensa como desafiante, de restitución del diálogo necesitará inscribirse y desarrollarse en los tiempos que el amor revolucionario, en cuanto proceso, supone:

El tiempo del otro como tiempo hechizado. Tiempo pavoroso en el que el otro es siempre desconocido [...]. El tiempo de la apertura de sí a este encantamiento. Este tiempo implica percibirse como otro [...]. [y, por último] El tiempo interminable. A saber, el de la permanencia en la experiencia del diálogo. (Tiburi, 2018, pp. 47-48)

Solo entonces será posible asumir teóricamente, pero sobre todo desde la práctica, la infinidad del otro que también somos, como alteridad inagotable. Esta, y no otra, es la exigencia de la democracia como lazo amoroso.

\section{Sobre el autor}

Julio César Mazo González. Filósofo de la Universidad Externado de Colombia. Magíster en Literatura y Cultura del Instituto Caro y Cuervo. Docente investigador del programa de Filosofía de la Facultad de Ciencias Sociales y Humanas (Universidad Externado de Colombia). Áreas de interés: Crítica descolonial, filosofía política, estética. Editor del libro Decir y dejarse decir: diálogos en torno al cuerpo, el tiempo y espacio (en proceso). En 2017 y 2018 recibió el reconocimiento Profesor del Año, por parte de la Corporación Universitaria Unitec, Área de Sociohumanística. 


\section{Referencias}

Agamben, G. (1996). La comunidad que viene. Pre-Textos.

Badiou, A. (2011). Elogio del amor. Esfera de los Libros.

Badiou, A. (2013). La filosofía y el acontecimiento. Amorrortu.

Badiou, A. (2008). El balcón del presente. Siglo XXI.

Bauman, Z. (2007). Tiempos líquidos. Vivir en una época de incertidumbre. Tusquets Editores.

Butler, J. (2017). Cuerpos aliados y lucha política. Hacia una teoría performativa de la asamblea. Paidós Básica.

Bouteldja, H. (2017a). Los blancos, los judíos y nosotros. Hacia una política del amor revolucionario. Akal.

Bouteldja, H. (2017b). "Por una política del amor revolucionario". Demodiversidad. Imaginar nuevas posibilidades democráticas (pp. 155-161). Akal.

Bruckner, P. (2011). La paradoja del amor. Una reflexión actual sobre las pasiones. Tusquets Editores.

Castro-Gómez, S. (2019). El tonto y los canallas. Notas para un republicanismo transmoderno. Pontificia Universidad Javeriana.

Castro-Gómez, S. (2017). Revoluciones sin sujeto. Slavoj Žižek y la crítica del historicismo posmoderno. Akal.

Costa Matos, A. S. M. (2015). Filosofía radical y utopía: inapropiabilidad, an-arquía, anomia. Siglo del Hombre Editores.

Deleuze, G. (2008). En medio de Spinoza. Cactus.

Dussel, E. (2016). Filosofías del sur. Descolonización y transmodernidad. Akal.

Genet, J. (2018). Prefacio a Los hermanos de soledad. Virus.

Grosfoguel, R. (2011). La descolonización del conocimiento: diálogo crítico entre la visión descolonial de Franzt Fanon y la sociología descolonial de Boaventura de Sousa Santos. Formas-Otras: saber, nombrar, narrar, hacer, Barcelona, IV Training Seminar de Jóvenes Investigadores en Dinámicas Interculturales (pp. 97-108). Fundación CIDOB. 
Grosfoguel, R. (2016). La descolonización de la economía política y los estudios poscoloniales: transmodernidad, pensamiento descolonial y colonialidad global. Epistemologías del Sur (perspectivas) (pp. 373-405). Akal.

Holloway, J. (1995). Historia y marxismo abierto. Dialéctica (pp. 94-107). Nueva Época.

Hoyos, I. (2018). La resistencia spinozista contra el abuso político del miedo. Totalitarismo: la resistencia filosófica (pp. 53-74). Madrid, Tecnos.

Kristeva, J. (1999). El porvenir de la revuelta. Fondo de Cultura Económica.

Laclau, E. (1996). Universalismo, particularismo y la cuestión de la identidad. Emancipación y diferencia (pp. 43-68). Ariel.

Lazzarato, M. (2013). La fábrica del hombre endeudado: ensayo sobre la condición neoliberal. Amorrortu.

Lefort, C. (2004). La incertidumbre democrática: ensayos sobre lo político. Anthropos.

Lévinas, E. (2003). De otro modo de ser o más allá de la esencia. Sígueme.

MacPherson, C. B. (2005). La teoría política del individualismo posesivo: de Hobbes a Locke. Trotta.

Masolo, D. A. (2016). Filosofía y conocimiento indígena: una perspectiva africana. Epistemologías del Sur (perspectivas) (pp. 517-537). Akal.

Modonesi, M. (2016). El principio antagonista. Marxismo y acción política. Universidad Nacional Autónoma de México.

Monedero, J. C. (2017). Política tras la derrota de la política: posdemocracia, pospolítica y populismo. Demodiversidad. Imaginar nuevas posibilidades democráticas (pp. 199-228). Akal.

Negri, A. (2000). Spinoza subversivo. Variaciones inactuales. Akal.

Nietzsche, F. (2010). La rivalidad homérica. Cinco prólogos para cinco libros no escritos (pp. 46-90). Arena Libros.

Rivera Cusicanqui, S. (2011). Ch’ixinakax Utxiwa. Una reflexión sobre prácticas y discursos descolonizadores. Tinta Limón.

Spinoza, B. (2011). Tratado político. Gredos.

Tiburi, M. (2018). ¿Cómo conversar con un fascista? Reflexiones sobre el autoritarismo de la vida cotidiana. Akal.

Hallazgos

ISSN: 1794-3841 | e-ISSN: 2422-409X | DOI: https://doi.org/10.15332/2422409X

Vol. 18 N.o 36| julio-diciembre del 2021 